\title{
Inhibition by Mercurial Reagents and Role of SH Groups of the Adenosine Triphosphatase from Escherichia coli 414 Membranes
}

\author{
By OMAR AZOCAR AND EMILIO MUÑOZ \\ Sección Bioquímica de Membranas, Instituto de Inmunología y Biología \\ Microbiana, C.S.I.C., Madrid-6, Spain
}

(Received 28 April 1978)

\begin{abstract}
Mercurials selectively inhibited Escherichia coli 414 ATPase (EC 3.6.1.3). Inhibition of the soluble ATPase $\left(\mathrm{BF}_{1}\right)$ was greater than for the membrane-bound enzyme. The titration of $4 \mathrm{SH}$ groups per mol $\mathrm{BF}_{1}$ with $0.05 \mathrm{~mm}-p$-chloromercuri $\left[{ }^{14} \mathrm{C}\right]$ benzoate showed a good dose-response curve for the inhibition of basal ATPase but not for the trypsin-stimulated activity. Accessible SH groups did not seem to be related to the active site of the enzyme. Mercurials appeared to affect $E$ : coli ATPase by inducing a molecular change in the holoenzyme, followed by dissociation. One to two SH groups with different degrees of accessibility were located in the $\alpha$ and $\gamma$ subunits of ATPase $\left(\mathrm{BF}_{1}\right)$ but only one was located in the $\beta$ subunit, irrespective of the concentration of $p$-chloromercuribenzoic acid, suggesting a structural role for $\mathrm{SH}$ groups in $\mathrm{BF}_{1}$.
\end{abstract}

\section{INTRODUCTION}

Of the specific components of the energy-transducing machinery, the ATPases or coupling factors $F_{1}$ (EC 3.6.1.3) have been most actively investigated owing to the ease with which they may be solubilized, so allowing their purification and molecular characterization (Penefsky, 1974; Abrams \& Smith, 1974; Pedersen, 1975; Nelson, 1976). The $F_{1}$ factors from mitochondria and chloroplasts (Penefsky, 1974; Nelson, 1976) have been thoroughly studied but studies on bacterial ATPases or $\mathrm{BF}_{1}$ factors have been less comprehensive. Studies carried out in our laboratory on the water-soluble ATPase portion ( $\mathrm{BF}_{1}$ factor) of the ATPase-ATP synthetase complex from two strains of Micrococcus lysodeikticus (Andreu et al., 1973; Carreira et al., 1976; Carreira et al., 1977) and one strain of Escherichia coli (Azocar \& Muñoz, 1977) have demonstrated differences between bacterial energytransducing ATPases (Andreu et al., 1973; Carreira et al., 1977; Azocar \& Muñoz, 1977). A similar conclusion on possible differences in the molecular structure of mitochondrial and chloroplast $F_{1}$ was reached in recent studies on the analysis of the cross-linked products from both these ATPases (Baird \& Hammes, 1976, 1977). At present, a comparative biochemical study of $F_{1}$ factors from different origins appears to be worthwhile for understanding the structure-function relationships of these energy-transducing proteins.

One of the less explored areas in the study of $\mathrm{BF}_{1}$ factors is the possible involvement of $\mathrm{SH}$ groups in their structure and function. Both mitochondrial and chloroplast ATPases contain 12 half-cystines per molecule - eight SH and four in two disulphide bonds (Senior, 1975; Farron \& Racker, 1970). On the other hand, the half-cystine content of bacterial ATPases is seldom cited in the literature and, when available, appears to be much lower than that of mitochondrial and chloroplast ATPases (Andreu et al., 1973; Monteil et al., 1975). Apart from some indirect observations that $p$-chloromercuribenzoate or other $\mathrm{SH}$ 
reagents inhibited the membrane ATPase from $E$. coli strains and Streptococcus faecalis (Evans, 1969; Kobayashi \& Anraku, 1972; Gunther et al., 1974; Nelson et al., 1974; Ahlers et al., 1975), the effect of such inhibitors on $\mathrm{BF}_{1}$ has not been studied. In a recent report, we demonstrated the role of thiol groups and disulphide bridges in maintaining the structural integrity of the cytoplasmic membrane from E. coli K12 (Azocar \& Muñoz, 1976). These results prompted us to investigate the significance of thiol group modification on the properties of the membrane ATPase from E. coli 414. The present report describes the selective effect of mercurial reagents on the properties of this ATPase in its membranebound and soluble states. This effect has been examined on the unmasked ATPase activity, referred to as basal activity, as well on the latent activity which may be elicited by trypsin digestion of the natural inhibitor of the ATPase (trypsin-stimulated activity). Inhibition of ATPase is probably the consequence of a dissociation of the holoenzyme induced by the action of the reagents on accessible SH groups. This effect has not hitherto been reported and suggests a role for SH groups in the structural domains of the protein, for example, at the inter-subunit regions. Under the same experimental conditions, purified ATPase $\mathrm{BF}_{1}$ from $M$. lysodeikticus was not affected by the mercurial reagents.

\section{METHODS}

Organisms. Escherichia coli 414 (Hfr, thr), a derivative of strain $\mathrm{k} 12$, which was a gift from Dr J. Puig (Universidad de los Andes, Mérida, Venezuela), and Micrococcus lysodeikticus strain PWYE or strain A (Andreu et al., 1973; Carreira et al., 1976) were grown as previously described (Corao et al., 1974; Carreira \& Muñoz, 1975; Carreira et al., 1976).

Membrane isolation; solubilization and purification of ATPase. Membrane 'ghosts' were isolated by the sequential treatment of exponentially growing $E$. coli with EDTA and lysozyme as described previously (Corao et al., 1974; Carreira \& Muñoz, 1975). Membranes were kept as pellets for periods of not longer than 1 week and were used as a source of membrane-bound ATPase after resuspending them in $30 \mathrm{~mm}$-Tris/ $\mathrm{HCl}$, pH 7.5, containing $1 \mathrm{~mm}-\mathrm{MgCl}_{2}$ at about $1 \mathrm{mg}$ protein $\mathrm{ml}^{-1}$. The ATPase of $E$. coli was solubilized by suspending the $\mathrm{Mg}^{2+}$-free membrane pellets in $50 \mathrm{~mm}$-Tris/ $\mathrm{HCl}$, $\mathrm{pH} 9 \cdot 0$, containing $3 \mathrm{mM}$-EDTA for $15 \mathrm{~min}$ at the same protein concentration as above; the enzyme remained in the supernatant after centrifugation at $27000 \mathrm{~g}$ (Carreira et al., 1973; Carreira \& Muñoz, 1975). Soluble ATPase was obtained by filtering the supernatant through an Amicon Diaflo PM-10 membrane (1 to $\left.1.5 \mathrm{kgf} \mathrm{cm}^{-2}\right)$ to eliminate EDTA (Azocar \& Muñoz, 1977). The ATPase was purified by molecular sieving as described elsewhere (Azocar \& Muñoz, 1977).

Membranes and ATPase from $M$. lysodeikticus strain A were obtained as previously described (Muñoz et al., 1969; Andreu et al., 1973; Andreu \& Muñoz, 1975).

Assay of ATPase activity. Basal and trypsin-stimulated activities of E. coli preparations were measured using $8 \mathrm{mM}$-ATP in the presence of $4 \mathrm{mM}-\mathrm{MgCl}_{2}$ essentially as described by Carreira \& Muñoz (1975). This substrate concentration was about sevenfold higher than that required for half-saturation of the enzyme. Activity of M. lysodeikticus ATPase was measured using $8 \mathrm{~mm}-\mathrm{ATP} / \mathrm{Ca}^{2+}$ as substrate and the conditions previously described (Muñoz et al., 1969).

The effect of thiol reagents on ATPase activity was tested by preincubating ATPase preparations with any of the reagents at final concentrations ranging from $10 \mu \mathrm{M}$ to $3 \mathrm{mM}$. Occasionally, an excess of dithiothreitol was added at the end of the incubation with the thiol reagent to reverse its effect.

Determination of SH groups in E. coli ATPase preparations. Thiol groups were determined either with $1 \mathrm{~mm}-$ 5,5'-dithiobis(2-nitrobenzoic acid) (DTNB) as described by Azocar \& Muñoz (1976), or by measuring the retention on nitrocellulose filters of the complex formed between $p$-chloromercuri[ $\left.{ }^{[4} \mathrm{C}\right]$ benzoic acid $(\mathrm{CMB})$ and protein SH groups, following the procedure described by Krakov \& Goolsby (1971).

Polyacrylamide gel electrophoresis and identification of bands labelled with p-chloromercuri $\left[{ }^{14} \mathrm{C}\right]$ benzoate. Gel electrophoresis was carried out at $\mathrm{pH} 8 \cdot 5 \pm 0.1$ using the Tris/glycine system or at $\mathrm{pH} 7.5$ using the Tris/ acetate system as described by Azocar \& Muñoz (1977). Gels $(11 \times 0.5 \mathrm{~cm})$ containing $7 \%(\mathrm{w} / \mathrm{v})$ acrylamide were used in both cases. Sodium dodecyl sulphate (SDS)-polyacrylamide gel electrophoresis was carried out as described above but with the addition of $0.1 \%(\mathrm{w} / \mathrm{v})$ SDS to both gels, and buffer and samples were pretreated with $8 \mathrm{mg}$ SDS (mg protein) ${ }^{-1}$.

Proteins were stained with Coomassie 250 as described by Andreu $e t$ al. (1973). The distribution of radioactivity in protein was followed by laterally slicing the gels into $0.8 \mathrm{~mm}$ discs with a Mickle Gel Slicer and treating the slices as follows. To each slice, $0.3 \mathrm{ml} 0 \cdot 1 \%(\mathrm{w} / \mathrm{v}) \mathrm{SDS}$ was added; the slices were then frozen and thawed three times, shaken overnight at $30^{\circ} \mathrm{C}$ and suspended in Bray's solution (Bray, 1960). Alternatively, 
the slices were directly soaked in $3 \mathrm{ml}$ of a scintillation solution containing $0.5 \%(\mathrm{w} / \mathrm{v}) 2-\left(4^{\prime}\right.$-tert-butylphenyl)5-(4"-biphenylyl)-1,3,4-oxadiazole (butyl-PBD) and $33 \%(\mathrm{v} / \mathrm{v})$ Triton X-100 in toluene and counted after $1 \mathrm{~h}$ shaking. The efficiency of counting ${ }^{14} \mathrm{C}$ was $40 \%$ by both methods, though the latter method was less timeconsuming.

\section{RESULTS}

Quantitative distribution of $S H$ groups in E. coli membranes and soluble ATPase

The soluble ATPase fraction from $E$. coli membranes, representing $10 \%$ of total membrane protein, contained $0.9 \mathrm{~mol}$ accessible $\mathrm{SH}$ groups $(50 \mathrm{~kg} \text { protein })^{-1}$, as measured by titration with DTNB and, following denaturation with SDS, $1.8 \mathrm{~mol}$ total $\mathrm{SH}(50 \mathrm{~kg}$ protein $)^{-1}$. The whole membranes contained $0.8 \mathrm{~mol}$ accessible $\mathrm{SH}$ (50 kg protein $)^{-1}$ and $3.4 \mathrm{~mol}$ total SH (50 kg protein) ${ }^{-1}$. Therefore, the soluble ATPase was less enriched in SH than the whole membranes, though its thiol groups were more accessible to titration with DTNB without denaturation of the protein. Thus, the SH groups measured with SDS present in the soluble ATPase preparation accounted for only $5 \%$ of the total $\mathrm{SH}$ of membranes while those titrated without SDS represented $11 \%$ of the membrane accessible SH groups.

\section{Effect of thiol reagents on ATPase activity of E. coli membranes and soluble fraction}

Thiol reagents inhibited $E$. coli ATPase (Table 1). The most effective inhibitor was CMB, followed by $\mathrm{Hg}^{2+}$, DTNB, and the alkylating agents. Differences in sensitivity to these inhibitors were found between the membrane-bound and the soluble forms of ATPase, on one hand, and between the basal and trypsin-stimulated activities, on the other. The membrane-bound ATPase was only partially inhibited by CMB and the inhibition was greater for the trypsin-stimulated activity than for the basal activity. The level of inhibition reached with $10 \mu \mathrm{M}$-CMB was not increased by increasing the CMB concentration to $1 \mathrm{mM}$. However, for the soluble ATPase, the basal and trypsin-stimulated activities were inhibited to a similar extent by a given concentration of CMB and this inhibition increased from about $30 \%$ to $90 \%$ when the CMB concentration was increased from $0.1 \mathrm{~mm}$ to $0.3 \mathrm{mM}$.

The substrates, ATP and $\mathrm{Mg}^{2+}$, protected the soluble and purified $E$. coli ATPase preparations from inhibition by CMB but they showed little protection for the membranebound enzyme (Table 2).

Table 1. Effect of different thiol reagents on the activity of membrane-bound and soluble ATPase from E. coli 414

The ATPase preparations ( $1 \mathrm{mg}$ membrane protein $\mathrm{ml}^{-1}$ or $200 \mu \mathrm{g}$ soluble protein $\mathrm{ml}^{-1}$ in $30 \mathrm{mM}-$ Tris/ $\mathbf{H C l}, \mathrm{pH} 7 \cdot 5$ ) were incubated with different concentrations of the reagents listed below for 30 to $45 \mathrm{~min}$ at room temperature and subsequently analysed for ATPase activity.

\begin{tabular}{|c|c|c|c|c|}
\hline \multirow[b]{2}{*}{ Enzyme preparation } & \multirow[b]{2}{*}{ Reagent } & \multirow[b]{2}{*}{$\begin{array}{c}\text { Concn } \\
(\mathrm{mM})\end{array}$} & \multicolumn{2}{|c|}{ Inhibition $(\%)$} \\
\hline & & & $\begin{array}{c}\text { Basal } \\
\text { ATPase }\end{array}$ & $\begin{array}{c}\text { Trypsin- } \\
\text { stimulated } \\
\text { ATPase }\end{array}$ \\
\hline Membrane-bound & $\begin{array}{l}\text { CMB } \\
\text { DTNB } \\
N \text {-Ethylmaleimide } \\
\text { Iodoacetamide }\end{array}$ & $\begin{array}{c}0.01-1.00 \\
0.25-1.00 \\
1.00 \\
0.10-2.00\end{array}$ & $\begin{array}{r}20 \\
0 \\
0 \\
0\end{array}$ & $\begin{array}{r}48 \\
0 \\
0 \\
0\end{array}$ \\
\hline Soluble & $\begin{array}{l}\text { CMB } \\
\text { CMB } \\
\mathrm{Hg}^{2+} \\
\text { DTNB } \\
N \text {-Ethylmaleimide } \\
\text { lodoacetamide or }\end{array}$ & $\begin{array}{c}0 \cdot 01-0 \cdot 10 \\
0 \cdot 30-1 \cdot 00 \\
0 \cdot 33 \\
0 \cdot 25-1 \cdot 00 \\
0 \cdot 50-3 \cdot 00 \\
0 \cdot 10-2 \cdot 00\end{array}$ & $\begin{array}{c}24 \\
84 \\
31 \\
15 \pm 5 \\
16 \pm 5 \\
0-10\end{array}$ & $\begin{array}{c}35 \\
92 \\
22 \\
21 \pm 10 \\
23 \pm 6 \\
0-15\end{array}$ \\
\hline
\end{tabular}


Table 2. Effect of ATP and $\mathrm{Mg}^{2+}$ on the inhibition by p-chloromercuribenzoic acid of the membrane-bound and soluble ATPase from E. coli 414

The ATPase preparations $\left(1 \mathrm{mg}\right.$ membrane protein $\mathrm{ml}^{-1}$ or $200 \mu \mathrm{g}$ soluble protein $\mathrm{ml}^{-1}$ in $30 \mathrm{mM}-$ Tris $/ \mathrm{HCl}, \mathrm{pH} \mathrm{7.5)}$ were incubated with $1 \mathrm{mM}-\mathrm{CMB}$ alone or in the presence of $10 \mathrm{mM}-\mathrm{Mg}^{2+}$ or $10 \mathrm{mM}$-ATP for $45 \mathrm{~min}$ at room temperature and subsequently analysed for ATPase activity.

$\begin{array}{llcc}\text { Enzyme preparation } & \text { Addition } & \begin{array}{c}\text { Basal } \\ \text { ATPase }\end{array} & \begin{array}{c}\text { Inhibition } \\ \text { stimulated } \\ \text { ATPase }\end{array} \\ \text { Membrane-bound } & \text { None } & 20 & 42 \\ & \text { Mgen } & 12 & 48 \\ \text { Soluble } & \text { ATP } & 16 & 40 \\ & \text { None } & 84 & 92 \\ \text { Purified } & \text { Mge } & 22 & 56 \\ & \text { ATP } & 25 & 63 \\ & \text { None } & 77 & 82 \\ & \text { Mge } & 28 & 56 \\ & \text { ATP } & 18 & 40\end{array}$

Under identical experimental conditions, neither the membrane-bound ATPase nor the purified enzyme from $M$. lysodeikticus was inhibited by any of the SH reagents. Thus, these results show a clear difference between the ATPases of $M$. lysodeikticus and $E$. coli and suggest the existence of subclasses of accessible SH groups in E. coli ATPase.

\section{Titration of SH groups in purified E. coli ATPase and inhibition of its activity}

The possible existence of different classes of accessible $\mathrm{SH}$ groups was examined by attempting to correlate inhibition of the ATPase activity with titratable SH groups. The titration of $4 \mathrm{SH}$ groups per molecule of enzyme was accompanied by inhibition of the basal activity of purified ATPase (Fig. 1). The correlation between inhibition and titration of SH groups was less good for the trypsin-stimulated activity. At $0.03 \mathrm{~mm}-\mathrm{CMB}$ only $20 \%$ inhibition of the latter activity was observed while the inhibition increased to $40 \%$ at $0.05 \mathrm{~mm}-\mathrm{CMB}$ though the number of $\mathrm{SH}$ groups titrated remained the same. At concentrations of CMB which produced about $80 \%$ inhibition of $E$. coli ATPase (see Tables 1 and 2) there was no correlation between the level of inhibition and the titration of 2 to 3 additional SH groups (Table 3). These observations confirmed the existence of subclasses of SH groups in E. coli ATPase, yet suggested that thiol groups were not involved in the active site of E. coli ATPase.

\section{Effect of $C M B$ on E. coli ATPase as studied by gel electrophoresis}

In view of the last suggestion, the possibility that $\mathrm{CMB}$ may induce structural changes in $E$. coli ATPase was examined by gel electrophoresis. In both electrophoretic systems, samples treated with CMB showed a decrease in the level of ATPase holoenzyme, that is, in bands of relative mobility 0.10 in Tris/acetate buffer and relative mobility 0.24 in Tris/ glycine buffer (Fig. 2). The effect was more evident when the electrophoresis was carried out at $\mathrm{pH} 8 \cdot 5$. Under these conditions the enzyme is very sensitive to any environmental alteration (Azocar \& Muñoz, 1977). The addition of dithiothreitol to the incubation mixtures and during gel electrophoresis reversed the molecular changes induced by CMB. Other mercurials such as $\mathrm{Hg}^{2+}$ or mersalyc acid induced a similar structural change, possibly a dissociation, in E. coli ATPase.

Radioactivity was detected in three bands following similar experiments using $\left[{ }^{14} \mathrm{C}\right] \mathrm{CMB}$ (Fig. $2 c$ ). One band corresponded to ATPase holoenzyme and the other two bands (relative 


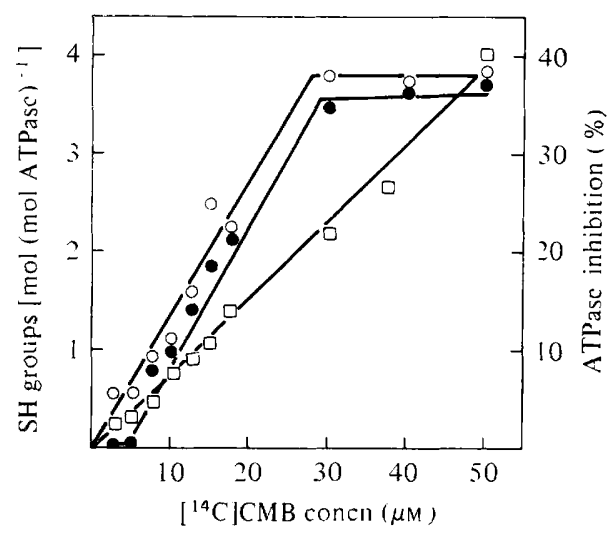

Fig. 1. Titration of SH groups in purified E. coli ATPase and inhibition of its activity by p-chloromercuribenzoic acid. Samples of purified ATPase $(150 \mu \mathrm{g})$ in $500 \mu 130 \mathrm{~mm}$-Tris $/ \mathrm{HCl}, \mathrm{pH} 7 \cdot 5$, were incubated at $20^{\circ} \mathrm{C}$ with various concentrations of $\left[{ }^{14} \mathrm{C}\right] \mathrm{CMB}$ (specific activity $1.05 \times 10^{6}$ c.p.m. $\mu \mathrm{mol}^{-1}$ ). After $45 \mathrm{~min}, 100 \mu \mathrm{l}$ portions (containing about $10 \mu \mathrm{g}$ protein) were removed for assay of basal and trypsin-stimulated ATPase activity. The residual volume $(300 \mu l)$ was filtered through nitrocellulose filters and the complexes formed between $\left[{ }^{14} \mathrm{C}\right] \mathrm{CMB}$ and protein $\mathrm{SH}$ groups were measured (Krakow \& Goolsby, 1971). O, mol SH titrated; O, inhibition of basal ATPase; $\square$, inhibition of trypsin-stimulated ATPase.

Table 3. Inhibition of purified ATPase from E. coli 414 by p-chloromercuribenzoic acid and correlation with titration of its $S H$ groups

Purified E. coli ATPase $(100 \mu \mathrm{g})$ was incubated with different concentrations of $\left[{ }^{14} \mathrm{C}\right] \mathrm{CMB}$ (specific activity $1.05 \times 10^{6} \mathrm{c}$.p.m. $\mu \mathrm{mol}^{-1}$ ) in $500 \mu \mathrm{l} 30 \mathrm{~mm}$-Tris $/ \mathrm{HCl}, \mathrm{pH} 7.5$, for $45 \mathrm{~min}$ at $20^{\circ} \mathrm{C}$. After incubation, portions (containing about $10 \mu \mathrm{g}$ protein) were removed for assay of ATPase activity and the remainder of the mixture was filtered. The filters were washed with $1 \mathrm{ml} 100 \mathrm{~mm}-\mathrm{Tris} / \mathrm{HCl}$, pH 7.5 and dried, and radioactivity was counted either directly or in the presence of $3 \mathrm{ml}$ Bray's solution (Bray, 1960).

$\begin{array}{cccc}\begin{array}{c}\text { CMB concn } \\ \text { (mM) }\end{array} & \begin{array}{c}\text { Basal } \\ \text { ATPase }\end{array} & \begin{array}{c}\text { Trypsin- } \\ \text { stimulated } \\ \text { ATPase }\end{array} & \begin{array}{c}\text { SH groups } \\ \text { [mol (mol ATPase) }{ }^{-1} \text { ] }\end{array} \\ 0.03 & 38 & 20 & 4 \\ 0.05 & 38 & 40 & 4 \\ 0.30 & 75 & 80 & 4-5 \\ 1.00 & 77 & 82 & 6-7\end{array}$

mobilities 0.84 and 0.86 ) corresponded to the major subunits. These components were identified by eluting the appropriate bands and subjecting them to SDS-polyacrylamide gel electrophoresis.

Location of SH groups in the subunits of E. coli ATPase

Exposure of $E$. coli ATPase to two different $\left[{ }^{14} \mathrm{C}\right] \mathrm{CMB}$ concentrations yielded qualitatively similar radioactivity profiles on SDS-polyacrylamide gel electrophoresis (Fig. 3). Radioactivity was incorporated into the $\alpha, \beta$ and $\gamma$ subunits, but quantitative differences between subunits were observed. The $\alpha$ and $\gamma$ subunits were more heavily labelled after exposure to $1 \mathrm{mM}-\left[{ }^{14} \mathrm{C}\right] \mathrm{CMB}$. At $50 \mu \mathrm{M}-\mathrm{CMB}$, the $\alpha, \beta$ and $\gamma$ subunits contained about $1 \mathrm{~mol}$ labelled SH per mol polypeptide, while at $1 \mathrm{mM}-\mathrm{CMB}, 2 \mathrm{~mol}$ of $\mathrm{SH}$ per mol of $\alpha$ and $\gamma$ subunits were labelled. These results are therefore consistent with those reported in Table 3. 

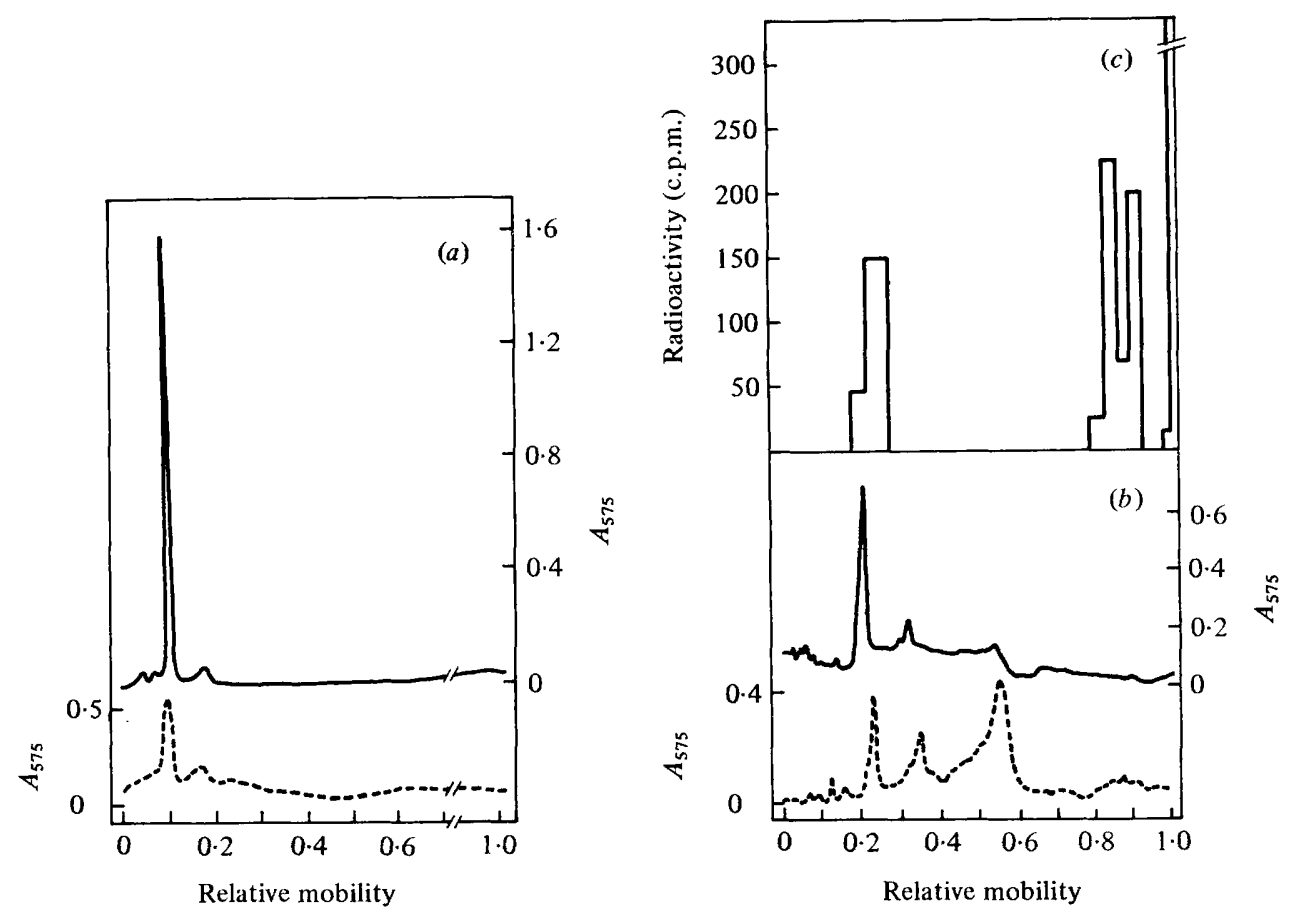

Fig. 2. Polyacrylamide gel electrophoresis of purified ATPase from $E$. coli 414 showing the effect of CMB. Purified ATPase (15 $\mu \mathrm{g})$ in $100 \mu \mathrm{l} 30 \mathrm{mM}$-Tris $/ \mathrm{HCl}$, pH 7.5, was incubated $(a, b)$ with (- - ) or without $(-) 1 \mathrm{~mm}$ unlabelled CMB or $(c)$ with $\left[{ }^{14} \mathrm{C}\right] \mathrm{CMB}$ (specific activity $2 \times 10^{5} \mathrm{c}$.p.m. $\mu \mathrm{mol}^{-1}$ ). After $45 \mathrm{~min}$ at $20^{\circ} \mathrm{C}$, mixtures were electrophoresed in $(a)$ Tris/acetate, $\mathrm{pH} 7 \cdot 5$, or $(b, c)$ Tris/ glycine, $\mathrm{pH} 8 \cdot 5$. Migration was towards the anode $(+)$.

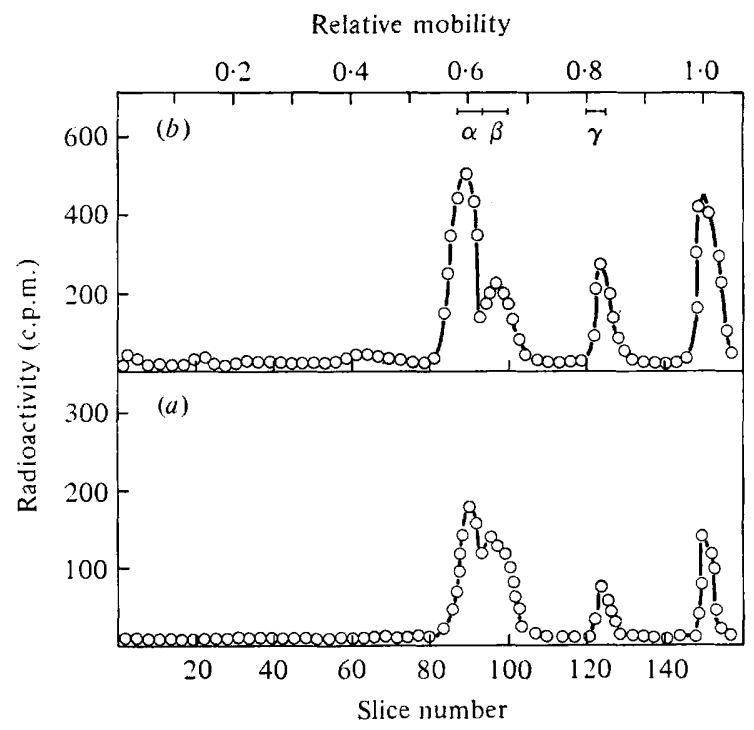

Fig. 3. Sodium dodecyl sulphate-polyacrylamide gel electrophoresis of purified E. coli ATPase labelled with $\left[{ }^{14} \mathrm{C}\right] \mathrm{CMB}$. Samples of purified ATPase $(50 \mu \mathrm{g})$ were incubated with either $(a) 0.05 \mathrm{mM}-$ $\left[{ }^{14} \mathrm{C}\right] \mathrm{CMB}$ or $(b) 1 \mathrm{~mm}-\left[{ }^{14} \mathrm{C}\right] \mathrm{CMB}$ (specific activity $1.05 \times 10^{6}$ or $2 \times 10^{5}$ c.p.m. $\mu \mathrm{mol}^{-1}$, respectively) for $45 \mathrm{~min}$ at $20^{\circ} \mathrm{C}$. The labelled protein was separated from excess reagent by Sephadex G-25 gel chromatography on a column $(0.9 \times 25 \mathrm{~cm})$ and then dissociated with $1 \%(\mathrm{w} / \mathrm{v})$ SDS. The dissociated samples were electrophoresed in Tris/glycine, $\mathrm{pH} 8.5$, containing $0.1 \%(\mathrm{w} / \mathrm{v})$ SDS and the gels were treated as described in Methods. Bars indicate the positions of the $\alpha, \beta$ and $\gamma$ subunits. 


\section{DISCUSSION}

The mechanism by which mercurial reagents inhibited E. coli ATPase deserves comment. On one hand, the concentration-response curve of basal ATPase activity was correlated with the modification of $4 \mathrm{~mol} \mathrm{SH}$ per mol enzyme suggesting that these SH groups were involved in the binding or hydrolytic site of the ATPase. However, the lack of correlation between the titration of these $4 \mathrm{SH}$ groups and the inhibition of the trypsin-stimulated activity argued against this suggestion. The latter observation was supported by labelling experiments with $\left[{ }^{14} \mathrm{C}\right] \mathrm{CMB}$ which yielded $50 \%$ of the label in dissociation products of the ATPase (see Fig. 2).

Taken together, the results suggest that free, accessible $\mathrm{SH}$ groups are not directly involved in the binding or catalytic site of $E$. coli ATPase. The evidence points to a different mechanism of inhibition. It appears likely that inhibition of $E$. coli ATPase by mercurials results from profound structural change and concomitant dissociation of the holoenzyme. This effect is reminiscent of that observed on depletion of $\mathrm{Mg}^{2+}$ from $E$. coli $\mathrm{K} 12$ ATPase by EDTA (Azocar \& Muñoz, 1977). It is therefore tempting to suggest that mercurials affect $E$. coli ATPase by their ability to chelate and/or compete with divalent cations. This may account for the selective action of these reagents on E. coli ATPase. Alternatively, the selective effect of mercurials may be related to their relative greater hydrophobicity compared with other SH group reagents since the effectiveness of these reagents in inhibiting $E$. coli ATPase correlated with their degree of hydrophobicity (see Table 1). Mersalyc acid was also a potent inhibitor of $E$. coli ATPase. Irrespective of their exact mode of action, the effect of mercurials on $E$. coli ATPase was on thiol groups, as confirmed by reversal of their effect by dithiothreitol.

These studies have provided evidence for the existence of subclasses of SH groups in $E$. coli ATPase, including the presence of buried SH groups. One subclass of accessible SH groups, present in approximately equimolar amounts in the $\alpha, \beta$ and $\gamma$ subunits, was modified by low concentrations of CMB. Another class, only present in $\alpha$ and $\gamma$ subunits, required higher concentrations of CMB before reaction occurred.

The studies reported here provide new insight into the idea that energy-transducing proteins display differences in molecular organization. Under the same experimental conditions, $M$. lysodeikticus and $E$. coli ATPases behaved differently in their sensitivity to mercurials. We do not know whether the inhibition by mercurials reported here is a general property of the ATPases from all E. coli strains or is strain-specific.

Our observations on E. coli ATPase agree with those of Pedersen (1976), who found a selective inhibitory effect of mercurials on the bicarbonate stimulated-ATPase activity of mitochondrial $F_{1}$ and related it to a conformational change of the mitochondrial enzyme rather than to a direct involvement of $\mathrm{SH}$ groups at the catalytic site.

We are indebted to the Fondo Nacional para el Desarrollo de la Investigación and the Consejo Superior de Investigaciones Científicas for financial support. We thank Miss Pilar Palacios for skilful technical assistance.

\section{REFERENCES}

Abrams, A. \& SMith, J. B. (1974). Bacterial membrane ATPase. In The Enzymes, vol. X, pp. 395429. Edited by P.D. Boyer. New York and London: Academic Press.

Ahlers, J., Kabisch, D. \& Gunther, T. (1975). The functional groups of the Mg-Ca ATPase from Escherichia coli. Canadian Journal of Biochemistry 5, 658-665.
Andreu, J. M. \& MuÑoz, E. (1975). Micrococcus lysodeikticus ATPase. Purification by preparative gel electrophoresis and subunit structure studied by urea and sodium dodecylsulfate gel electrophoresis. Biochimica et biophysica acta 387, 228233.

Andreu, J. M., Albendea, J. A. \& Muñoz, E. (1973). Membrane adenosine triphosphatase of 
Micrococcus lysodeikticus. Molecular properties of the purified enzyme unstimulated by trypsin. European Journal of Biochemistry 37, 505-515.

AzocaR, O. \& MuÑoz, E. (1976). Molecular organization in bacterial cell membranes. Sulphydryl groups and disulfide bridges in Streptomyces albus and Escherichia coli $\mathrm{K} 12$ cytoplasmic membranes. European Journal of Biochemistry 68, 245-254.

Azocar, O. \& MuÑoz, E. (1977). Extrinsic and intrinsic factors that influence inactivation and purification of the unstable adenosine triphosphatase solubilized from membranes of an Escherichia coli K12 strain. Biochimica et biophysica acta 482, 438452.

BaiRd, B. A. \& Hammes, G. G. (1976). Chemical cross-linking studies of chloroplast coupling factor 1. Journal of Biological Chemistry 251, 6953-6962.

BaIRD, B. A. \& Hammes, G. G. (1977). Chemical cross-linking studies of beef heart mitochondrial coupling factor 1. Journal of Biological Chemistry 252, 4743-4748.

Bray, G. A. (1960). A simple efficient liquid scintillator for counting aqueous solutions in a liquid scintillation counter. Analytical Biochemistry 1, 279-285.

Carreira, J. \& MUÑoz, E. (1975). Membrane bound and soluble adenosine triphosphatase of Escherichia coli $\mathrm{K} 12$. Kinetic properties of the basal and trypsin-stimulated activities. Molecular and $\mathrm{Cel}$ lular Biochemistry 9, 85-95.

Carreira, J., Leal, J. A., Rojas, M. \& Muñoz, E. (1973). Membrane ATPase of Escherichia coli $\mathbf{K} 12$. Selective solubilization of the enzyme and its stimulation by trypsin in the soluble and membrane-bound states. Biochimica et biophysica acta 307, 541-556.

Carreira, J., Andreu, J. M., Nieto, M. \& Muñoz, E. (1976). Membrane adenosine triphosphatase of Micrococcus lysodeikticus. Isolation of two forms of the enzyme complex and correlation between enzymatic stability, latency and activity. Molecular and Cellular Biochemistry 10, 67-76.

Carreira, J., Andreu, J. M. \& Muñoz, E. (1977). Differential sensitivity to trypsin digestion of purified forms of Micrococcus lysodeikticus ATPase $\left(\mathrm{BF}_{1}\right)$. A study of their structural and conformational differences and mechanism of conversion. Biochimica et biophysica acta 492, 387-398.

Corao, M. de, Serrano, J. A., Leal, J. A., Puig, J. \& MuÑoz, E. (1974). Isolation of murein-free spheroplast 'ghosts' from a strain of Escherichia coli K12. Microbiología española 27, 283-298.
Evans, D. J., JR (1969). Membrane adenosine triphosphatase of Escherichia coli: activation by calcium ions and inhibition by monovalent cations. Journal of Bacteriology 100, 914-922.

FARRON, F. \& RACKER, E. (1970). Studies on the mechanism of the conversion of coupling factor 1 from chloroplasts to an active adenosine triphosphatase. Biochemistry 9, 3829-3836.

Gunther, T., Pellnitz, W. \& Maris, G. (1974). Effect of salts on the activity and inhibition of $E$. coli membrane ATPase by ethacrynic acid and inhibitors. Zeitschrift für Naturforschung 29, 5459.

Kobayashi, H. \& ANRAKU, Y. (1972). Membranebound adenosine triphosphatase of Escherichia coli. I. Partial purification and properties. Journal of Biochemistry 71, 387-399.

Krakow, J. S. \& Goolsby, S. P. (1971). A membrane filter assay for protein sulphydryl groups. Biochemical and Biophysical Research Communications 44, 453-458.

Monteil, H., Roussel, G. \& Boulouis, D. (1975). Membrane ATPase of Proteus L-forms. Solubilization and molecular properties. Biochimica et biophysica acta 382, 465-478.

Muñoz, E., Salton, M. R. J., NG, M. H. \& Schor, M. T. (1969). Membrane adenosine triphosphatase of Micrococcus lysodeikticus. Purification, properties of the 'soluble' enzyme and properties of the membrane-bound enzyme. European Journal of Biochemistry 7, 490-501.

NELSON, N. (1976). Structure and function of chloroplast ATPase. Biochimica et biophysica acta 456, 314-338.

Nelson, N., KanNeR, B. I. \& GurniCK, D. L. (1974). Purification and properties of $\mathrm{Mg}^{+2}-\mathrm{Ca}^{2+}$ adenosine triphosphatase from Escherichia coli. Proceedings of the National Academy of Sciences of the United States of America 71, 2720-2724.

Pedersen, P. L. (1975). Mitochondrial adenosine triphosphatase. Journal of Bioenergetics 6, 243-275.

Pedersen, P. L. (1976). Adenosine triphosphatase from rat liver mitochondria. Evidence for a mercurial-sensitive site for the activating anion bicarbonate. Biochemical and Biophysical Research Communications 71, 1182-1188.

Penefsky, H. S. (1974). Mitochondrial and chloroplast ATPases. In The Enzymes, vol. X, pp. 375394. Edited by P. D. Boyer. New York and London: Academic Press.

SENIOR, A. E. (1975). Relationship of cysteine and tyrosine residues to adenosine triphosphate hydrolysis by mitochondrial adenosine triphosphatase. Biochemistry 12, 3622-3627. 